\title{
Necrobiosis Lipoidica - A Rare Cutaneous Complication of Diabetes Mellitus
}

\section{Osokina Irina $\mathbf{V}^{*}$}

Science Centre of the Siberian Branch of Russian Academy of Science, Krasnoyarsk, Russia

*Corresponding Author: Osokina Irina V, Science Centre of the Siberian Branch of Russian Academy of Science, Krasnoyarsk, Russia.

Received: October 21, 2019; Published: November 04, 2019

DOI: $10.31080 /$ ASNH.2019.03.0521

\begin{abstract}
Introduction: Necrobiosis lipoidica (NL) is a rare chronic granulomatous dermatitis that usually appears in the lower extremities. It affects about $0.3-3.2 \%$ of diabetic patients, the majority of whom have type 1 diabetes. The etiology and pathogenesis of this disorder are still unclear. NL depends on the diabetes control and lipid metabolism. NL usually affects the shins, sometimes diffuse NL forms are have hotbeds on body, backs of hands and feet. The average onset is 30 years, with females being affected more commonly. NL is a difficult disease to manage despite a large treatment options that include topical corticosteroids, immunomodulators, biologics, platelet inhibitors, phototherapy, and surgery. LN complications such as ulceration are common, and lesions should also be monitored for transition to squamous cell carcinoma. There are very few reported cases of necrobiosis lipoidica in children.

Case Report: We report a case of diffuse necrobiosis lipoidica in a 17 year old girl with type 1 diabetes mellitus (16.5 years disease duration). In the suspect of necrobiosis lipoidica, a skin biopsy was performed (lower extremities and interscapular area). The microscopic evaluation was suggestive of necrobiosis lipoidica.

Conclusion: In patients with T1DM, diagnosis of NL of the lower legs is usually unequivocal. However, diagnosis may be more challenging in the presence of lesions with recent onset and/or atypical clinical presentation and unusual site. In these cases, NL must always be taken in consideration in order to avoid misdiagnosis, wrong/late treatment decisions and progression to ulceration. Keywords: Type 1 Diabetes; Necrobiosis Lipoidica; Skin Lesion; Granulomatous Dermatitis; Children
\end{abstract}

\section{Introduction}

Necrobiosis lipoidica (NL) is a rare chronic granulomatous dermatitis that usually appears in the lower extremities. It affects about $0.3-3.2 \%$ of diabetic patients, the majority of whom have type 1 diabetes. The etiology and pathogenesis of this disorder are still unclear. NL depends on the diabetes control and lipid metabolism. NL usually affects the shins, sometimes diffuse NL forms are have hotbeds on body, backs of hands and feet. The average onset is 30 years, with females being affected more commonly. NL is a difficult disease to manage despite a large treatment options that include topical corticosteroids, immunomodulators, biologics, platelet inhibitors, phototherapy, and surgery. LN complications such as ulceration are common, and lesions should also be monitored for transition to squamous cell carcinoma. There are very few reported cases of necrobiosis lipoidica in children.

\section{Case Report}

The patient, a Caucasian 17-y-old girl, was born at term with weight $3400 \mathrm{~g}$, healthy parents. The age of the mother at birth of the child was 37 years. The breast feeding was 6 months. Type 1 diabetes (T1DM) had been diagnosed at the age of 9 months in the ketoacidosis. The hyperglycemia, often ketoacidosis and growth delay were observed before 10 years. Than the patient had a good glycemic control (HbA1c 6.8\% - 7.5\%).The first NLD lesion had been diagnosed at the age of 2 years on the back and on the right leg. Three new lesions appeared at the age of 5-8 years: on the left arm and leg. At the age of 10 , seven infiltrated, reddish patches, with slight central atrophy were evident on the skin.

On physical examination, height $1.61 \mathrm{~m}$, weight $53 \mathrm{~kg}$. On the skin of the back, on the right hand, on the front surface of shanks - 7 polymorphous hotbeds of necrobiosis lipoidica diabeticorum, 60$80 \mathrm{~mm}$ in diameter, dark-red and brown with cyanosis. On shanks in centers of NLD hotbeds there is lamellate peeling (Picture 1,2). A heart rate of 72 beats per minute, blood pressure - 110/70 mm $\mathrm{Hg}$, and a respiratory rate of 20 breaths per minute. Pubertal stage: P3 A3 Ma3 Me 0. The girl has psychological problems connected with NLD.

Biochemical evaluation revealed $\mathrm{HbA} 1 \mathrm{c}$ level 6.8\% (normal range, $4 \%$ to $6 \%$ ), glycemia 110 to $170 \mathrm{mg} / \mathrm{L}$ during a day, high total cholesterol level $378 \mathrm{mg} / \mathrm{dL}$; triglycerides level $375 \mathrm{mg} / \mathrm{dL}$ (normal range, 101 to $150 \mathrm{mg} / \mathrm{dL}$ ), low density lipoprotein level $60.1 \mathrm{mg} / \mathrm{dL}$; LH level $0.8 \mathrm{nmol} / \mathrm{L}$ (normal range, 4 to $25 \mathrm{nmol} / \mathrm{L}$ ), FSH level $1.9 \mathrm{nmol} / \mathrm{L}$ (normal range, 5 to $20 \mathrm{nmol} / \mathrm{L}$ ); a thyrotropin level of $3.2 \mathrm{mIU}$ per liter (normal range, 0.4 to 4.2 ), a free thyroxine level of $1.7 \mathrm{ng}$ per deciliter (normal range, 0.8 to $2.2 \mathrm{ng}$ per deci- 


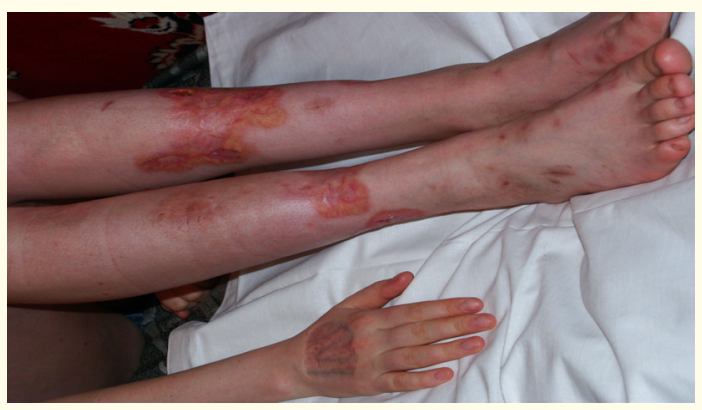

Picture 1

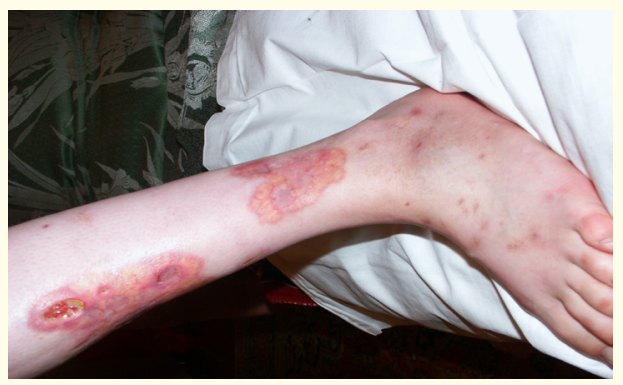

Picture 2

liter); microalbuminuria $99.3 \mathrm{mg} / \mathrm{ml}$ (normal range, 0 to $25 \mathrm{mg}$ / $\mathrm{ml})$.

Histological features of NLD showed foci of collagen degeneration with sclerosis, surrounded by a chronic, mainly perivascular, granulomatous infiltrate, made up of lymphocytes and histiocytes.

Therapy: Diet, insulin therapy in multiple daily injection (MDI) regimen (Humalog 6-10 $\mathrm{U}$ before each main meal; Lantus at bedtime $20 \mathrm{U}$; $42 \mathrm{U}$ per day, $0.75 \mathrm{U}$ per kg); ciprofibrate $100 \mathrm{mg}$ daily.

Necrobiosis lipoidica diabeticorum in this patient was as result poor diabetes control first ten years. But even with good metabolic control there are evident disturbances of lipid metabolism [1-12].

\section{Conclusion}

In patients with T1DM, diagnosis of NL of the lower legs is usually unequivocal. However, diagnosis may be more challenging in the presence of lesions with recent onset and/or atypical clinical presentation and unusual site. In these cases, NL must always be taken in consideration in order to avoid misdiagnosis, wrong/late treatment decisions and progression to ulceration.

\section{Bibliography}

1. Tong Lana X., et al. Dermatology Online Journal 24.12 (2018): 1-3.

2. Pourang Aunna Sivamani and Raja K. "Treatment-resistant ulcerative necrobiosis lipoidica in a diabetic patient responsive to ustekinumab". Dermatology Online Journal 25.8 (2019): 1-4.

3. Erfurt-Berge C., et al. "Update on clinical and laboratory features in necrobiosis lipoidica: a retrospective multicenter study of 52 patients". European Journal of Dermatology 22 (2012): 770-775.

4. Jockenhofer F., et al. "Cofactors and comorbidities of necrobiosis lipoidica: analysis of the German DRG data from 2012".Journal der Deutschen Dermatologischen Gesellschaft 14 (2016): 277-284.

5. Sibbald C., et al. "Necrobiosis Lipoidica". Clinics in Dermatology 33 (2015): 343-360.

6. Reid SD., et al. "Update on necrobiosis lipoidica: a review of etiology, diagnosis, and treatment options". Journal of the American Academy of Dermatology 69 (2013): 783-791.

7. Osokina IV. "Epidemiological and immunogenetic features of iodine deficiency diseases and diabetes mellitus among indigenous and outside population of Central Siberia". Ph.D. thesis. Moscow, (2002): 1-289.

8. Osokina IV. "Immunogenetic, hormonal and metabolic peculiarities of insulin-dependent diabetes mellitus in early childhood". MD thesis. Moscow (1992): 1-149.

9. Ignatiev P., et al. "The problems of late diagnostic of diabetes mellitus type 2 in Yakuts". Yakut Medical Journal 1 (2009): C. 79-82.

10. Osokina IV. "Immunogenetic aspects of type 1 diabetes mellitus". Novosibirsk (2012): 1-110.

11. Osokina IV. "A 17-year-old girl with diabetes mellitus type 1 and diffuse necrobiosis lipoidica diabeticorum". Hormone Research in Paediatrics 88 (2016): 622-623.

12. Osokina DE., et al. "HLA-antigens and necrobiosis lipoidica diabeticorum in children with type 1 diabetes". Pediatric Diabetes (2006): 89-90.

Volume 3 Issue 12 December 2019

(C) All rights are reserved by Osokina Irina V., et al. 